\title{
PANEL DATA TESTS OF PPP: A CRITICAL OVERVIEW*
}

\author{
Guglielmo Maria Caporale \\ Brunel University, London \\ Mario Cerrato \\ London Metropolitan University
}

\begin{abstract}
This paper reviews recent developments in the analysis of non-stationary panels, focusing on empirical applications of panel unit root and cointegration tests in the context of PPP. It highlights various drawbacks of existing methods. First, unit root tests suffer from severe size distortions in the presence of negative moving average errors. Second, the common demeaning procedure to correct for the bias resulting from homogeneous cross-sectional dependence is not effective; more worryingly, it introduces cross-correlation when it is not already present. Third, standard corrections for the case of heterogeneous cross-sectional dependence do not generally produce consistent estimators. Fourth, if there is between-group correlation in the innovations, the SURE estimator is affected by similar problems to FGLS methods, and does not necessarily outperform OLS. Finally, cointegration between different groups in the panel could also be a source of size distortions. We offer some empirical guidelines to deal with these problems, but conclude that panel methods are unlikely to solve the PPP puzzle.
\end{abstract}

Keywords: Purchasing Power Parity (PPP), Panel Unit Root and Cointegration Tests, Cross-Sectional Dependence

JEL Classification: C23, F31

Corresponding author: Professor Guglielmo Maria Caporale, Brunel Business School, University, Uxbridge, Middlesex UB8 3PH, UK.

Email: Guglielmo-Maria.Caporale@brunel.ac.uk

\footnotetext{
${ }^{*}$ We wish to thank Joseph Pearlman for useful comments and suggestions, and Nick Sarantis for kindly supplying the dataset.
} 


\section{Introduction}

The theory of Purchasing Power Parity (PPP) was introduced by Cassell (1918), and is based on the notion that the exchange rate depends on relative price levels. Researchers have tested long-run PPP employing a variety of both univariate and multivariate tests. Early tests such as the ADF (augmented Dickey-Fuller) and Johansen's maximum likelihood methods have provided little support for relative PPP. However, these tests have low power if there is high persistence in the model, i.e. a dominant root close to, but not exactly equal to unity (see $\mathrm{Ng}$ and Perron, 1999), or if the sample size is not sufficiently large. Specifically, Froot and Rogoff (1995) have argued that unit root tests fail to reject the null hypothesis because of the lack of data. It has been suggested, therefore, that panel unit root tests, which have higher power, should be used instead, and these have more frequently indicated mean reversion in real exchange rates. In particular, the procedures developed by Levin and Lin (1993) and Im et al (1997) have been widely used. More recently, multivariate tests have been proposed by Larsson et al (2001) and Pedroni (1997).

Although panel unit root tests and cointegration tests have higher power, they are not a panacea, as their asymptotic distribution is derived in many cases under the assumption that the error terms are not cross-correlated, and therefore the tests are not valid when this assumption is violated. To circumvent this problem, Maddala and $\mathrm{Wu}$ (1999) suggest using bootstrapped distributions to draw statistical inference, while Pedroni (1997) recommends GLS-based corrections.

Further, the assumption of homogeneity across sectional units required by many such tests is often too restrictive. In the case of PPP, it would imply, under the alternative hypothesis of stationarity, that the speed of convergence to PPP is the same for each country in the panel, which is rather implausible. Im et al (1997) and Pedroni (1999) have introduced tests allowing for heterogeneity across the sectional units.

Finally, many cointegration tests do not allow for multiple cointegrating vectors. Larsson et al (2001) have addressed this issue in the context of panel cointegration methods.

This paper reviews critically the panel unit root and cointegration tests most commonly used in the literature on PPP, and some of their empirical applications. Therefore, it differs significantly from earlier surveys either of PPP studies (see, e.g., Froot and Rogoff, 1995, Rogoff, 1996, Sarno and Taylor, 2002, and Taylor, 2003), or 
of panel data econometrics (see Hall and Urga, 2000, Banerjee, 1999, McCoskey and Kao, 1999, and Phillips and Moon, 2001). Unlike earlier contributions of the former type, which tend to be rather comprehensive, but mention only briefly panel data studies on PPP (see, e.g. Taylor, 2003), the present review focuses exclusively on attempts to shed light on PPP by exploiting recent advances in panel data econometrics. Compared to the latter, it provides a more detailed analysis of recent developments in the analysis of non-stationary panels (whilst Hall and Urga, 2000, for example, devote a large proportion of their paper to the stationary case), including further issues whose importance has become clear in the last few years (thereby updating Banerjee, 1999, and Phillips and Moon, 2001), arising from the presence of negative moving average components in the time series (which affect the information criteria generally used for lag selections), cross-sectional cointegration, crosssectional dependence, and, finally, the existence of multiple cointegrating vectors. Moreover, the emphasis is on the empirical application of these techniques in the context of PPP. ${ }^{1}$ In addition to discussing earlier studies on PPP, we provide some new empirical examples, and offer some guidelines to the applied researcher.

In particular, we highlight various drawbacks of standard panel data methods which represent important challenges for future research. First, unit root tests suffer from severe size distortions in the presence of negative moving average errors, especially if a small lag length is selected on the basis of standard information criteria (see Ng and Perron, 1999). Second, the demeaning procedure (see Im et al, 1997) commonly employed to correct for the bias resulting from homogeneous crosssectional dependence (which is crucial to ensure the applicability of the central limit theorem and derive the asymptotic distributions of the estimators) is in fact not effective: it does not eliminate the problem even for a large number of equations in the system. More worryingly, it introduces cross-correlation into the system when it is not already present. Third, the corrections normally used in the case of heterogeneous cross-sectional dependence (see Pedroni, 1999 and O'Connell, 1998) do not generally produce consistent estimators (see Coakley et al, 2002). Fourth, in the presence of between-group correlation in the innovations, the SURE estimator usually recommended is affected by similar problems to FGLS methods, and does not necessarily outperform OLS (see Maddala, 2002). Finally, cointegration between

\footnotetext{
${ }^{1}$ McCoskey and Kao (1999) also show how to apply some of these techniques in practice, but
} 
different groups in the panel could also be a source of size distortions (see Banerjee et al, 2001). We show that the aforementioned issues are relevant when testing for PPP, and recommend an appropriate empirical strategy, but conclude that panel methods are unlikely to solve the PPP puzzle.

The paper is organised as follows. Section 2 briefly summarises the theory of PPP, and considers the main existing panel unit root tests. Section 3 moves on to panel cointegration tests. Section 4 discusses unresolved issues in panel data tests. Section 5 concludes.

\section{Panel Unit Root Tests and PPP}

\subsection{The Theory of PPP}

PPP suggests that, once converted to a common currency, national and foreign price levels should be equal. It relies on the idea that goods market arbitrage enforces parity in prices across countries, and can be illustrated by making a distinction between absolute and relative PPP. The starting point for most derivations of PPP is the law of one price (LOP), which states that for any good i

$$
P_{i}=S P_{i}^{*}
$$

where $P_{i}$ is the domestic currency price of good $\mathrm{i}, P_{i}^{*}$ is the foreign currency price, and $\mathrm{S}$ is the domestic currency price of foreign exchange.

Equation (1) states that the domestic price of good $i$ is equal to the price of the same good abroad multiplied by the nominal exchange rate (S). Absolute PPP states that the exchange rate is a ratio of the domestic to the foreign price level:

$$
S=P / P^{*}
$$

where $\mathrm{S}$ is the nominal exchange rate as defined above, $\mathrm{P}$ and $P^{*}$ are the domestic and foreign price level respectively.

their concern is with the "twin deficits" problem. 
Often equation (2) appears in logarithmic form as

$$
s=p-p^{*}
$$

where lower case letters denote natural logarithms.

Measuring PPP appropriately is an important issue. Price indices are not constructed for an internationally standardised basket of goods, but only for different domestic baskets. Furthermore, they are constructed in the form of indices relative to a base period. Because the indices give no indication of how large absolute PPP deviations were for the base period, one must assume that absolute PPP held on average over that period. On a practical level, relative PPP is used to circumvent these problems. In this case, even if countries use different price weights, changes in relative price levels will be reflected in the relative price index.

Relative PPP requires that changes in relative price levels be offset by changes in the nominal exchange rate:

$$
\Delta p_{t}=\Delta p_{t}^{*}+\Delta s_{t}
$$

In equation (3), the choice of an appropriate price index to measure the nominal exchange rate is crucial. For instance, there is much stronger evidence of stationarity for the WPI- rather than CPI-based real exchange rate. This is because the WPI index contains a larger proportion of tradable goods. In general, if the exchange rate is seen as the relative price of traded commodities, the appropriate price index should include only traded goods, whilst if it is viewed as an asset price (the relative price of two currencies), both traded and non-traded goods and services should be included in a broader price index, such as the GNP deflator or the CPI (see MacDonald, 1994).

Most of the literature on PPP in the 1980s tested for the stationarity of the real exchange rate $\mathrm{q}_{\mathrm{t}}$ using DF and ADF tests, since by definition 


$$
q_{t}=s_{t}-p_{t}+p_{t}^{*}
$$

where $s_{t}$ is the logarithm of the nominal exchange rate, $p_{t}$ the logarithm of the domestic price level, and $p_{t}^{*}$ the logarithm of the foreign price level.

If PPP holds, the real exchange rate will revert to its long-run equilibrium value given by PPP after being hit by shocks. The null hypothesis is that it follows a random walk (has a unit root), since market efficiency implies that its changes should be unpredictable, whilst the alternative is that PPP holds.

Most researchers failed to reject the null of a unit root during the recent float period for bilateral rates against the US dollar, but not for European currencies against the German mark (see, for example, Mark 1990, Meese and Rogoff 1988). Longer time series were then used to deal with the low power of unit root tests (see, e.g., Lothian and Taylor, 1996). However, such studies suffer from spanning both fixed and flexible rate regimes; also, the basket used to construct the price indices is likely to be very different at the beginning and at the end of the sample.

\section{$2.2 \quad$ Panel Unit Root Tests}

An alternative approach to improving power is to increase the number of observations. In particular, researchers have suggested using panel data. A standard panel framework for PPP is:

$$
s_{i t}=\alpha+\beta\left(p_{i t}-p_{i t}^{*}\right)+\left(\sum_{i} D_{i}\right)+\left(\sum_{t} \delta_{t} D_{t}\right)+u_{i t}
$$

where $\mathrm{i}$ is the cross-sectional dimension, and $\mathrm{D}_{\mathrm{i}}$ and $\mathrm{D}_{t}$ are dummy variables, which denote, respectively, country-specific and time-specific effects.

A panel offers various advantages over traditional time series data in addition to the larger number of observations. First, using panel data may reduce the problem of multicollinearity: when the explanatory variables vary in two dimensions, they are less likely to be correlated. Furthermore, panel data are more informative about longrun behaviour than time series, which emphasise short-run behaviour. Finally, they may alleviate spurious regression problems (see Phillips and Moon, 1999).

Levin and Lin (1993) (LL) proposed the first panel data tests. They considered the following model: 


$$
\Delta q_{t}=\alpha_{i}+\phi_{t}+\beta q_{t-1}+c_{i} t+\xi_{i t}
$$

This model allows for fixed effects and unit-specific time trends in addition to common time effects. It is a direct extension of a univariate DF test to a panel data setting. It restricts the speed of convergence to long-run equilibrium under the alternative of stationarity to be the same for all countries. Furthermore, the errors are assumed to be independent across the units and to follow an invertible ARMA process:

$$
\xi_{i t}=\sum_{j=1}^{\infty} \theta_{i j} \xi_{i t-j}+\varepsilon_{i t}
$$

LL consider the use of pooled cross-section time series data to test the null hypothesis that each individual time series contains a unit root, against the alternative that each time series is stationary. Since $\beta$ is assumed to be the same for all observations, this is the same as testing the following null and alternative hypotheses:

$$
\begin{aligned}
& \mathrm{H}_{0}: \beta_{1}=\beta_{2}=\ldots \beta_{N}=1 \\
& \mathrm{H}_{1}: \beta_{1}=\beta_{2}=\ldots \beta_{N}<1
\end{aligned}
$$

The fact that $\beta$ is assumed to be the same for all observations represents a significant limitation of the LL1 test. Furthermore, both $\mathrm{N}$ and $\mathrm{T}$ are assumed to be sufficiently large, and $\mathrm{T}$ increases faster than $\mathrm{N}$ such that $N / T \rightarrow 0$ as both $\mathrm{N}$ and $\mathrm{T}$ $\rightarrow \infty^{2}$.

The test requires that the data are generated independently across individuals. However, LL show that this assumption can be relaxed to allow for a limited degree of dependence via time-specific effects. The influence of these effects can be removed by subtracting the cross-section average $y_{t}^{A}=\frac{1}{N} \sum_{i=1}^{N} y_{i t}$ from the observed data,

\footnotetext{
${ }^{2}$ On the basis of this rate of convergence, it is clear that for this test to work we have to have a much larger $\mathrm{T}$ in comparison to $\mathrm{N}$. This "superconsistency" assumption is requested, in particular, when the model contains individual specific effects. In this case the "superconsistency" assumption will ensure convergence of the test to a standard normal distribution. Harris and Tzavalis (1999) derive the limiting properties of unit root tests when $\mathrm{T}$ is fixed, which allows the derivation of the exact moments of the distribution.
} 
which does not affect the limiting distributions of the panel unit root and cointegration test statistics.

The strong assumptions required by the LL1 test led LL to develop a second test (LL2) with fewer restrictions. For instance, they showed that the assumption of no serial correlation can be relaxed, and that in fact adding lags of $\Delta q$ to a DF regression does not affect the limiting distribution of the test. Furthermore, the LL2 test allows the autoregressive parameters under the alternative hypothesis to vary across countries. The model corresponds to an unrestricted ADF model:

$$
\Delta q_{i t}=\alpha_{i}+\beta_{i} q_{i, t-1}+\sum_{k=1}^{m(i)} \lambda_{i, k} \Delta q_{i, t-k}+u_{i, t} \quad \mathrm{i}=1, . . \mathrm{N} \mathrm{t}=1, . . \mathrm{T}
$$

Three steps are required to obtain the test statistic $t_{B}^{*}$.

Step 1: Estimate $t_{B}$ by partitioning (8) as follows

$$
\begin{aligned}
& \Delta q_{i t}=\alpha_{i}+\sum_{k=1}^{m(i)} \lambda_{i, k} \Delta q_{i, t-k}+e_{i, t} \Rightarrow e_{i, t}^{*} \\
& q_{i t-1}=\alpha_{i}+\sum_{k=1}^{m(i)} \lambda_{i k} \Delta x_{i t-j}+v_{i t-1} \Rightarrow v_{i t-1}^{*}
\end{aligned}
$$

$e_{i t}^{*}$ is then regressed against $v_{i t-1}^{*}$ to obtain $\beta_{i}^{*}$ :

$$
e_{i t}^{*}=\beta_{i} v_{i t-1}^{*}+u_{i t}
$$

Since the residuals in the partitioned regression may display a large variance due to the heterogeneity of the series used, LL suggest the following adjustment:

$$
e_{i t}^{-}=\frac{e_{i t}^{*}}{\sigma_{u i}^{*}} \quad \text { and } \quad v_{i t-1}^{-}=\frac{v_{i t-1}^{*}}{\sigma_{u i}^{*}}
$$


where $\sigma_{e i}^{*}=\left(T-m_{i}-1\right)^{-1} \sum_{t=m_{i}+2}^{T}\left(e_{i t}^{*}-\beta_{i}^{*} v_{i t-1}\right)^{2}$

Step 2: For each series, compute the long-run variance:

$$
\begin{gathered}
\sigma_{q i}^{* 2}=(T-1)^{-1} \sum_{t=2}^{T} \Delta q_{i t}^{2}+2 \sum_{L=1}^{K} \omega K_{L}\left(\frac{1}{T-1} \sum_{t=2+L}^{T} \Delta q_{i t} \Delta q_{i t-L}\right) \\
\omega=\frac{1-L}{K+1} \quad \text { and } \quad K=3.21 T^{1 / 3}
\end{gathered}
$$

Compute the ratio of the estimated long-run variance and standard deviation:

$$
s_{i}^{*}=\frac{\sigma_{q i}^{*}}{\sigma_{e i}^{*}} \quad \text { and } \quad S_{N}^{*}=\frac{1}{N} \sum_{i=1}^{N} s_{i}^{*}
$$

Step 3: Estimate the panel regression (for all $\mathrm{i}$ and $\mathrm{t}$ ) and compute the test statistic:

$$
\begin{gathered}
e_{i t}^{-}=\beta \overline{v_{i t}}+u_{i t} \\
t_{B=0}=\frac{\beta^{*}}{\operatorname{RSE}\left(\beta^{*}\right)}
\end{gathered}
$$

where

$$
\begin{aligned}
& \operatorname{RSE}\left(\beta^{*}\right)=\sigma_{u}^{*}\left[\sum_{i=1}^{N} \sum_{t=m i+2}^{T} v_{i t-1}^{-}{ }^{1 / 2}\right. \\
& \sigma_{u}^{* 2}=(N T)^{-1} \sum_{i=1}^{N} \sum_{t=m i+2}^{T}\left(e_{i t}-\beta^{*} v_{i t-1}\right)^{2}
\end{aligned}
$$


The LL adjustment of (9) is given by:

$$
t_{\beta^{*}}=\frac{t_{\beta=0}-N T S_{N}^{*} \sigma_{u}^{*-2} R S E\left(\beta^{*}\right) \mu_{m T}}{\sigma_{m T}}
$$

where $\mu_{m T}$ and $\sigma_{m T}$ are mean and standard deviation adjustments computed using Monte Carlo methods.

As with the LL1 test, homogeneous cross-sectional dependence can be accommodated by expressing all variables as deviations from their time-specific means ${ }^{3}$.

In brief, the Levin and Lin (1993) tests raise various issues which the following literature has tried to address, such as the rate at which $\mathrm{T}$ and $\mathrm{N}$ are permitted to tend to infinity, homogeneity versus heterogeneity across $i$, the plausibility of the assumption that the error terms are independent across $i$, and the correction required in the presence of serial correlation.

Im et al (1997) proposed a unit root test for heterogeneous dynamic panels based on the mean-group approach. This test is similar to the LL2 one, in that it allows for heterogeneity across sectional units. The heterogeneous panel data model is the following:

$$
\Delta q_{i t}=\alpha_{i}+\beta_{i} q_{i, t-1}+\sum_{k=1}^{p} \phi_{i, k} \Delta q_{i, t-k}+\gamma_{i} t+u_{i t} \quad i=1, \ldots, N ; t=1, \ldots, T
$$

The model allows the speed of convergence to long-run equilibrium to vary across countries. The relevant hypotheses are:

$$
\mathrm{H}_{0}: \beta_{i}=0, \mathrm{H}_{1}: \beta_{i}<0 \mathrm{i}=1, \ldots \mathrm{N}_{1} ; \beta_{i}=0, \mathrm{i}=\mathrm{N}_{1}+1, \mathrm{~N}_{1}+2, \ldots \mathrm{N}
$$

\footnotetext{
${ }^{3}$ The LL tests have been widely used, finding support for the validity of long-run PPP (MacDonald 1996, Wu 1996 and Oh 1996). O Connell (1998) extends the results of LL. He demonstrates the importance of accounting for cross-sectional dependence among real exchange rates when testing for long-run PPP. He suggests using a feasible GLS (FGLS) estimator, and rejects PPP. His results have been reversed by Higgins and Zakrajsek (2000), who showed, using Monte Carlo methods, that the O'Connell truncation lag selection procedure leads to an overparameterisation of the AR and thus lack of power.
} 
Then, instead of pooling the data, one can perform separate unit root tests for the $\mathrm{N}$ cross-section units. Consider the t-test for each cross-section unit based on $\mathrm{T}$ observations. Let $t_{i}, i=1,2 \ldots N$ denote the t-statistics for testing unit roots, and let $\mathrm{E}\left(\mathrm{t}_{\mathrm{i}}\right)=\mathrm{u}$ and $\operatorname{var}\left(\mathrm{t}_{\mathrm{i}}\right)=\sigma^{2}$. Then:

$$
\sqrt{N} \frac{t-u}{\sigma}
$$

The problem one faces in using (11) is computing $u$ and $\sigma^{2}$. Im et al (1997) used Monte Carlo methods. Assuming that the cross sections are independent, they derived the following standardised t-bar statististic:

$$
t^{*}=\frac{\sqrt{N(T)}\left(t_{T}-E\left(t_{T}\right)\right)}{\sqrt{\operatorname{VAR}\left(t_{T}\right)}}
$$

where $t_{T}$ is the average t-statistic for each individual unit, and $E\left(t_{T}\right)$ and $\operatorname{Var}\left(t_{T}\right)$ are its mean and variance respectively.

The standardised t-bar statistic converges in probability to a standard normal distribution as $\mathrm{T}, \mathrm{N} \rightarrow \infty$ with a rate of convergence equal to $\sqrt{N}$. Therefore, the critical values from the lower tail of the normal distribution can be used.

Since the main result obtained by Im et al (1997) requires the observations to be generated independently across sections, and this assumption is likely to be violated, they propose the following adjustment. Assume that the error term in equation (10) comprises two random components:

$$
u_{i t}=\vartheta_{t}+\varepsilon_{i t}
$$


where $\vartheta_{t}$ is a stationary, time-specific common effect and $\varepsilon_{i t}$ is an idiosyncratic random effect. To deal with cross-sectional dependence the cross-sectional means should be subtracted from the observed data. ${ }^{4}$

Im et al (1997) also develop a second test, named the LM-bar statistic (Lagrange Multiplier):

$$
L M=\frac{\sqrt{N(T)}\left(L M_{T}-E\left(L M_{T}\right)\right)}{\left.\sqrt{\operatorname{VAR}\left(L M_{T}\right.}\right)}
$$

where $\mathrm{E}(\mathrm{LM})$ and $\mathrm{VAR}(\mathrm{LM})$ are the asymptotic values of the mean and the variance of the average LM statistics. ${ }^{5}$

Monte Carlo experiments on the Im et al (1997) test have shown that the t-bar test tends to have low power for a small T. Furthermore, in comparison with the LL2 test, it is very sensitive to the order of the underlying ADF regressions. Size distortion appears to be a serious matter when this is underestimated. However, when it is overestimated its empirical size is much closer to the nominal one. By contrast, the LL2 test tends to over-reject the null hypothesis, and the problem worsens as $\mathrm{N}$ increases. Finally, it seems to be affected by a rise in $\mathrm{T}$ more than in $\mathrm{N}$ (see Im et al, 1997, Maddala and Wu, 1999, Karlsson and Lothgren, 2000).

Karlsson and Lothgren (2000) have shown that, in general, the power of panel unit root tests (LL1, LL2, t-bar and LR-bar) depends on N, the number of series in the panel, $\mathrm{T}$, the time series dimension in each individual series, and the proportion of stationary series in the panel. For a given proportion of stationary series in the panel, the power increase due to a rise in $\mathrm{T}$ is larger than that resulting from a corresponding increase in $\mathrm{N}$. This means that the probability of rejecting the null hypothesis increases with T. Consequently, for large $\mathrm{T}$ we may reject the null even if it is not true. On the other hand, for small $\mathrm{T}$ we may accept the null when it is false.

Another unit root test for absolute PPP has been proposed by Koedijk et al. (1998). It has the important feature of being invariant to the choice of numeraire currency. Assume that PPP does not hold to the same extent for all currencies in the

\footnotetext{
${ }^{4}$ This procedure is the same as for LL1 and LL2.

${ }^{5}$ Coakley and Fuertes (1997) apply the Im et al (1997) procedure to a panel of 19 OECD countries in the 1973-96 period, and find evidence which supports the stationarity of the real exchange rate.
} 
panel. For each country in the panel we can investigate whether the value of its currency moves proportionally to the price level in that country:

$$
q_{i j}=\left(c_{i}-c_{j}\right)+\left(\delta_{i}-\delta_{j}\right) t+\beta_{i} p_{i}(t)-\beta_{j} p_{j}(t)-u_{i j}(t)
$$

where $\mathrm{c}$ is a constant term, $\mathrm{q}_{\mathrm{ij}}$ is the real exchange rate, $p_{i}$ and $p_{j}$ denote the log of the domestic consumer price index for country $\mathrm{i}, \mathrm{j}$ respectively, and $\mathrm{t}$ is a time trend. Koedijk et al (1998) estimate this equation simultaneously as a system of $\mathrm{N}$ equations for $\mathrm{N}$ exchange rates assuming that currency $\mathrm{j}=0$ is the common numeraire currency. Furthermore, to circumvent unit root and spurious regression problems they consider the hypothesis of relative PPP:

$$
\Delta_{k} q_{i j}(t)=\beta_{i} \Delta_{k} p_{i}(t)-\beta_{j} \Delta_{k} p_{j}(t)+u_{i j}(t)
$$

Since all the exchange rates are expressed in terms of a common base currency, in order to obtain more efficient estimates they use a GLS estimator. However, constructing a GLS estimator requires assumptions about the error term, which they model as the difference between the error term for country $i$ and $j$ :

$$
u_{i 0}=u_{i}(t)-u_{0}(t)
$$

Furthermore, they assume that country-specific shocks are uncorrelated and have constant variance equal to $\sigma^{2} / 2$ :

$$
\Sigma=\frac{1}{2} \sigma^{2}\left(\mathrm{I}+\Psi^{\prime}\right)
$$

where $\mathrm{I}$ is the identity matrix and $\psi^{\prime}$ a $(\mathrm{N} \times 1)$ vector of ones.

Since, under the above assumptions, the covariance matrix is completely specified, a GLS estimator can be used. The covariance structure given by (18) implies that all exchange rates in the panel have equal variance and that the 
correlation between them is $1 / 2$. It also ensures that all results are invariant with respect to the numeraire currency (Koedijk and Schotman, 1998) ${ }^{6}$.

A common feature of the unit root tests presented above is that they are invalid in the presence of cross-correlation between sections ${ }^{7}$. Bai and $\mathrm{Ng}$ (2002b) use a decomposition method to construct panel unit root tests that are robust to crosssectional dependence. Assume that the observed series $q_{i t}$ is generated as follows:

$$
q_{i t}=D_{i t}+\lambda_{i}^{\prime} F_{t}+e_{i t} \quad \mathrm{i}=1,2, \ldots, \mathrm{N}, \mathrm{t}=1,2, \ldots, \mathrm{T}
$$

The observed series is decomposed into three components: a deterministic component $\left(\mathrm{D}_{\mathrm{it}}\right)$, an unobservable factor $\left(\mathrm{F}_{\mathrm{t}}\right)$, and an idiosyncratic element $\left(\mathrm{e}_{\mathrm{it}}\right)$. The presence of the common factor in (19) implies correlation between different groups. Thus, pooled tests based on $q_{i t}$ are invalid. However, as generally assumed in factor analysis, the idiosyncratic component is cross-sectionally uncorrelated, so panel unit root tests can be developed focusing on the latter. For example, the Im et al (1997) tests on $q_{i t}$ would be invalid in this case, but the same tests on $e_{i t}^{*}$ (i.e. the estimate of $e_{i t}$ obtained by principal components) are valid. Furthermore, Bai and Ng (2002b) allow $F_{\mathrm{t}}$ and $e_{i t}$ to be integrated of different order. They describe their method as Panel Analysis of Non-stationarity in the Idiosyncratic and Common Components (PANIC). It can be summarised as follows. Assume the data are generated as in (20):

$$
\begin{gathered}
F_{m t}=\alpha_{m} F_{m t-1}+u_{m t} \quad \mathrm{~m}=1, \ldots, \mathrm{k} \\
e_{i t}=\rho_{i} e_{i t-1}+\varepsilon_{i t} \quad \mathrm{i}=1, \ldots, \mathrm{N}
\end{gathered}
$$

where $u_{m t}$ and $\varepsilon_{i t}$ are iid and mutually independent.

\footnotetext{
${ }^{6}$ They apply their procedure to a panel of 17 currencies (1972-1996), and show that evidence favouring PPP is stronger for the German mark and much weaker for the US dollar. However, the Koedijk et al. (1998) GLS estimator relies on very simplistic assumptions. In general, the assumption that country-specific shocks are uncorrelated is not a valid one. Coakley and Fuertes (2000) apply alternative tests to a panel of 19 OECD currencies (1973-1997), and find no evidence of the base currency effect once they have taken into account cross-sectional dependence. This is in contrast to earlier empirical findings in the literature on PPP using panel data methods.
} 
The factor $\mathrm{m}$ will not be stationary if $\alpha_{m}=1$; on the other hand, the idiosyncratic component will be stationary if $\rho_{i}<1$. Consequently, they suggest testing the following null and alternative hypotheses:

$$
\begin{aligned}
& H_{0}: \rho_{i}<0, \text { for all } \mathrm{i} \\
& H_{A}: \rho_{i}=1 \text { for some } \mathrm{i}
\end{aligned}
$$

They show that they can be tested using the KPSS test developed in Kwiatkowsky et al (1992) on the estimates of the two components (i.e. $F_{m t}^{*}$ and $e_{i t}^{*}$ ) obtained by using principal components analysis on equation (19). They also propose another panel unit root test, based on the SB statistic developed in Sargan and Bhargava (1983), named the modified SB (MSB). The procedure is the same as before. The test is applied to the estimates of $F_{m t}$ and $e_{i t}$ obtained by the method of principal components from equation (19), but the null hypothesis being tested is now $\rho_{i}=1$ for every i, i.e. a unit root null. Monte Carlo simulations reveal large size distortion for the KPSS test even when it is used to test $F_{m t}$ and $e_{i t}$ separately. Thus, this test rejects the stationarity null hypothesis too often. On the other hand, the MSB test has good size and power properties when it is used to test the components separately ${ }^{8}$.

Panel unit root tests have been criticised by Taylor and Sarno (1998) on the grounds that they have a high probability of rejecting the null hypothesis of joint nonstationarity of real exchange rates when just one real exchange rate series in the panel is mean reverting. ${ }^{9}$ The null hypothesis tested by many panel unit root tests is

\footnotetext{
${ }^{7}$ Note: even the t-bar test is invalid, and this is the reason why Im et al (1997) proposed a demeaning procedure. But, as we shall see, this procedure is particularly restrictive.

${ }^{8}$ They use this methodology to identify the source of non-stationarity in a panel of 21 quarterly real exchange rates, and find that a large number of exchange rates in the panel have a non-stationary idiosyncratic component.

9 According to Taylor and Sarno (1998), given the null hypothesis underlying panel unit root tests, the only possible alternative hypothesis is that at least one unit is a stationary process. Consequently, we may end up rejecting the null, even if only one series is stationary. However, this is not completely true since the alternative hypothesis underlying panel unit root tests are different and depend, crucially, on the degree of heterogeneity we assume. For example, in the LL1 test (that is a homogeneous test), the alternative hypothesis implies that all the series are stationary processes. If we increase the degree of heterogeneity under the alternative, we may also have that each series in the panel is a stationary process, or, as in the
} 
that all the series are realisations of I(1) processes. Taylor and Sarno (1998) suggest an alternative multivariate unit root test (Johansen JLR test), where the null hypothesis is rejected only if all the series are generated by mean reverting processes. Consider the following VAR representation:

$$
\Delta q_{t}=\Gamma+\Pi q_{t-1}+\sum_{j=1}^{L} \varphi_{i} \Delta q_{t-j}+v_{t} \quad \mathrm{t}=1, \ldots \mathrm{T}
$$

where $q_{t}=\left(q_{1 t}, q_{2 t}, \ldots, q_{N t}\right)^{\prime}, \Gamma$ is an $\mathrm{N} \times 1$ vector of constants, $\Pi$ is a $\mathrm{N} \times \mathrm{N}$ long-run multiplier matrix, and $v_{\mathrm{t}}$ is an $\mathrm{N} \times \mathrm{N}$ vector of disturbances and $v_{\mathrm{t}} \sim$ i.i.d. $\mathrm{N}(0, \Omega)$.

If each of the series is $\mathrm{I}(1)$ and no cointegration vector exists, the rank of $\Pi$ is equal to zero. If $\Pi$ is of full rank, this implies that all the series $q_{t}$ are realisations of stationary processes. The rank of a matrix is equal to the number of non-zero latent roots. In this context, stationarity of all the series means that $\Pi$ has full rank, and so $\mathrm{N}$ non-zero latent roots. Taylor and Sarno (1998) suggest testing the null that at least one series has a unit root, and the alternative that they all are stationary. This is the same as testing the null that $\Pi$ has less than full rank. Essentially this is a special case of Johansen`s likelihood ratio test for cointegration. The Johansen likelihood ratio (JLR) statistic is:

$$
\mathrm{JLR}=-\mathrm{T} \ln \left(1-\lambda_{\mathrm{N}}\right)
$$

This is shown to have a known $\chi^{2}$ distribution with one degree of freedom under the null hypothesis, with its empirical distribution being quite close to the asymptotic one for $\mathrm{T}>100 .{ }^{10}$ However, this test is reliable only when applied to a panel with a small cross-sectional dimension.

An alternative test, based on the $\mathrm{P}_{\lambda}$ test originally developed by Fisher (1932), is suggested by Maddala and Wu (1999), who show that it is more powerful than the t-bar test. Its disadvantage is that the significance levels have to be derived by means

Im et al (1997) test, that some units are stationary while others are not. The most heterogeneous test is the Maddala and Wu (1999) test.

${ }^{10}$ Taylor and Sarno (1998) apply the JLR test to a small panel of OECD countries (19731996), and find significant evidence of mean reversion for each of the real exchange rates. 
of Monte Carlo simulations. Maddala and Wu (1999) argue that while the Im et al (1997) test relaxes the assumption of homogeneity of the root across units, several difficulties still remain. Specifically, this test assumes that $\mathrm{T}$ is the same for all the cross-section units, and hence requires a balanced or complete panel (i.e. where the units are observed over the whole sample period). Also, it only allows for a limited amount of cross-correlation across units through common time effects. Maddala and $\mathrm{Wu}$ (1999) point out that, in practice, the cross-correlation is unlikely to take this simple form. They propose the following test. Let $\pi_{i}$ be the observed significance level (p-value) ${ }^{11} 12$ for the ith test. The $\mathrm{P}_{\lambda}$ test has a $\chi^{2}$ distribution with d.o.f. $2 \mathrm{~N}$, $P_{\lambda}=\sum_{i=1}^{N}\left(-2 \ln \pi_{i}\right)$, and it does not require a balanced panel. However, like the Im et al (1997) tests, it suffers from cross-sectional dependence. To solve the problem, Maddala and $\mathrm{Wu}$ (1999) suggest using bootstrap methods to obtain its empirical distribution. $^{13}$

\subsection{An Empirical Application}

In this sub-section we provide an empirical example by applying some of the panel unit root tests reviewed above to a panel of quarterly data exchange rates spanning the period 1973Q1-1998Q2. The series are taken from the IMF's International Financial Statistics, and are CPI-based real exchange rates. We allow first for heterogeneity under the alternative hypothesis, and then for both homogeneous and heterogeneous cross-sectional dependence. Specifically, we carry out the Im et al (1997) t-bar test and a modified version of the Maddala and Wu (1999) test. As already discussed, these tests are to be preferred, as they allow for heterogeneity under the alternative of stationarity. We take into account cross-sectional dependence by using two alternative methods, i.e. a demeaning procedure and non-parametric bootstrap, both of which are

\footnotetext{
${ }^{11}$ This is a crucial point, since it distinguishes the Fisher test, which is based on combining the significance levels of the different tests, from the t-test, which relies on combining the test statistics.

${ }_{12}$ Cerrato and Sarantis (2004) extend the Maddala and Wu (1999) test, and apply it to a panel of OECD CPI- and WPI-based real exchange rates, without finding any evidence of long-run PPP.

${ }^{13}$ Despite the availability of new panel unit root tests, many researchers have simply extended the DF and the ADF tests to a panel context (Lothian, 1997, Frankel and Rose, 1996, Papell, 1997). Papell (2002) considers the large swings in the US dollar during the 1980 by carrying out unit root tests modified to allow for restricted structural change, with mixed results.
} 
outlined in the previous section. Results for individual ADF statistics as well as multivariate panel unit root tests are reported in Table 1.

Table 1

\section{Unit Root tests of The Real Exchange Rate}

\begin{tabular}{|c|c|c|c|c|}
\hline Country & lags & ADF & P-Values & $\ln \left(\pi_{1}\right)$ \\
\hline Australia & 3 & -1.793 & 0.371 & -0.99155 \\
\hline Austria & 4 & -2.461 & 0.1225 & -2.09964 \\
\hline Belgium & 4 & -2.41 & 0.1335 & -2.01365 \\
\hline Canada & 6 & -1.41 & 0.5645 & -0.57181 \\
\hline Denmark & 3 & -2.19 & 0.216 & -1.53248 \\
\hline Finland & 7 & -2.81 & 0.05 & -2.99573 \\
\hline France & 4 & -2.56 & 0.096 & -2.34341 \\
\hline Germany & 4 & -2.54 & 0.104 & -2.26336 \\
\hline Greece & 4 & -2.29 & 0.161 & -1.82635 \\
\hline Ireland & 7 & -2.13 & 0.2175 & -1.52556 \\
\hline Italy & 4 & -2.55 & 0.1015 & -2.2877 \\
\hline Japan & 3 & -2.02 & 0.273 & -1.29828 \\
\hline Netherl. & 4 & -2.62 & 0.0865 & -2.44761 \\
\hline New Zeal. & 3 & -2.911 & 0.0455 & -3.09004 \\
\hline Norway & 7 & -2.36 & 0.145 & -1.93102 \\
\hline Portugal & 8 & -1.95 & 0.2855 & -1.25351 \\
\hline Spain & 8 & -2.64 & 0.0855 & -2.45924 \\
\hline Sweden & 8 & -2.82 & 0.0495 & -3.00578 \\
\hline Switz. & 4 & -2.44 & 0.127 & -2.06357 \\
\hline UK & 7 & -2.83 & 0.05 & -2.99573 \\
\hline \multicolumn{2}{|c|}{ t-bar (no-demeaning) } & -4.54 & & -40.996 \\
\hline t-bar (de & aning) & -3.65 & MW & 81.99209 \\
\hline \multicolumn{5}{|c|}{ Critical Values DF (5\%)- 2.89} \\
\hline \multicolumn{2}{|c|}{$\chi^{2}-(40)-5 \%$} & 55.8 & & \\
\hline
\end{tabular}

The number of lags in the ADF regression was chosen using the methodology suggested by Campbell and Perron (1997). When applying the Im et al (1997) t-bar test one has to be particularly careful in selecting the lag length for the ADF tests, since underestimating the true number of lags may lead to lack of power. As a first step, we implement individual ADF tests (see Table 1). We note that the ADF test rejects the unit root null only for New Zealand, providing very little evidence of stationarity of the real exchange rate. However, as previously mentioned, such tests have very low power against the null of a unit root. Therefore we also carry out panel unit root tests. The Im et al (1997) t-bar test has been obtained using equation (12) with $\mathrm{E}\left(t_{T}\right)$ and $\operatorname{Var}\left(t_{T}\right)$ as in $\operatorname{Im}$ et al (1997). The t-bar test with no demeaning strongly rejects the unit root null hypothesis. This result is confirmed by the demeaned t-bar test. The Maddala and Wu (1999) (MW) test relies on combining p- 
values rather than $\mathrm{t}$-statistics as the t-bar tests. P-values are obtained using the nonparametric bootstrap procedure described in Cerrato and Sarantis (2004). The Maddala and $\mathrm{Wu}$ (1999) also strongly rejects the unit root null. Overall, in line with most empirical studies on PPP, such as Coakley and Fuertes (1997) and Wu (1996) (Cerrato and Sarantis, 2004 being an exception ${ }^{14}$ ), panel unit root tests indicate that the real exchange rate is stationary over the sample period and the panel of countries we consider. ${ }^{15}$

\section{Panel Cointegration Tests and PPP}

\subsection{Panel Cointegration Tests}

Various researchers have used cointegration techniques to test PPP by estimating an equation such as:

$$
s_{t}=\alpha+\beta_{0} p_{t}+\beta_{1} p_{t}^{*}+u_{t}
$$

or, when symmetry between domestic and foreign prices was imposed, an equation such as:

$$
s_{t}=\alpha+\beta\left(p_{t}-p_{t}^{*}\right)
$$

Early tests were based on the idea that PPP in its weak form implies that $\mathrm{s}_{\mathrm{t}}, \mathrm{p}_{\mathrm{t}}$, and $p_{t}^{*}$ should be integrated of order one, I(1), and the residuals be stationary, $\mathrm{I}(0)$. PPP in its strong form holds if the joint symmetry and proportionality restrictions are also satisfied: $\beta_{0}=-\beta_{1}=1$. Numerous empirical studies have been carried out. In general, rejections of the null of cointegration are less frequent if CPI is used instead of WPI, and more frequent if the US dollar rather than the German mark is chosen as the numeraire currency. The Engle and Granger (1987) approach initially used is known to have low power against the null hypothesis of non-cointegration (in addition to restricting the cointegrating vector to be unique). The Johansen (1988) procedure,

\footnotetext{
${ }^{14}$ However, Cerrato and Sarantis (2004) use monthly data while the majority of other studies, except $\mathrm{Wu}(1996)$, use quartely data.

${ }^{15} \mathrm{Im}$ et al (1997) also reject the null hypothesis, whilst Maddala and Wu (1999) do not.
} 
which has higher power and allows for multiple cointegrating vectors, has subsequently been employed. ${ }^{16}$

Panel cointegration tests represented the next development. There are two main approaches, one based on the null hypothesis of cointegration, as in McCoskey and Kao (1998), the other on the null of no cointegration, as in Pedroni (1997, 1999). The former propose a residual-based Lagrange Multiplier test to deal with the nuisance parameters issue in a single equation model. The model is similar to those of Pedroni (1997) and Im et al (1997). Assume that $y_{i t}$ is generated as follows:

$$
y_{i, t}=\alpha_{i}+\beta_{i} x_{i, t}^{\prime}+e_{i, t}
$$

where $e_{i, t}=\theta \sum_{j=1}^{t} u_{i, j}+u_{i, t}$

The model allows for different slopes and intercepts, and the residuals are serially correlated. Furthermore, the regressors $\left(x_{i, t}^{\prime}\right)$ are assumed to be endogenous and generated by $x_{i, t}=x_{i, t-1}+\omega_{i, t}$, but not cointegrated. Under the null hypothesis $\mathrm{H}_{0}: \theta=0, \quad e_{i t}=u_{i t}$ and the above equation is a system of cointegrated regressors. McCoskey and Kao (1998) show that the test statistic is an LM statistic given by:

$$
L M=\frac{\sum_{i=1}^{N} \sum_{t=1}^{T} S_{i t}^{2}}{s^{2}}
$$

where $\mathrm{S}_{\mathrm{i}, \mathrm{t}}$ is the partial sum of the residuals, i.e $S_{i t}=\sum_{j=1}^{t} e_{i, j}^{*}$, and $\mathrm{s}^{2}$ is a consistent estimator of $\sigma^{2}$.

If we allow for correlation in the error processes ${ }^{17}, \mathrm{~s}^{2}$ can be estimated using the dynamic OLS estimator (DOLS) or the fully modified OLS estimator (FMOLS) ${ }^{18}$.

\footnotetext{
${ }^{16}$ Example of an empirical study using Johansen's tests to test PPP is Enders and Falk (1998).

${ }^{17}$ The serial correlation element could be particularly relevant in many empirical applications, including PPP.

${ }^{18}$ As we shall see, in general the DOLS estimator performs better than the FMOLS estimator.
} 
Define the test statistic based on the FM estimator as $\mathrm{LM}^{\mathrm{F}}$ :

$$
L M^{F}=\frac{\frac{1}{N} \sum_{i=1}^{N} \frac{1}{T^{2}} \sum_{t=1}^{T} S_{i t}^{F^{2}}}{\varpi^{F 2}}
$$

where $S^{F}{ }_{i t}=\sum_{j=1}^{t} e_{i j}^{F}$

and the long-run covariance matrix as:

$$
\varpi^{F}=\left[\begin{array}{ll}
\varpi_{11}^{F} & \varpi_{12}^{F} \\
\varpi_{21}^{F} & \varpi_{22}^{F}
\end{array}\right]
$$

McCoskey and Kao (1998) show that its asymptotic distribution is given by:

$$
\sqrt{N}\left(L M^{F}-u_{v}\right) \Rightarrow N\left(0, \delta_{v}^{2}\right)
$$

If we estimate $s^{2}$ using the DOLS estimator, we can construct a similar LM test with a similar limiting distribution. As in Im et al (1997), $\mathrm{u}_{\mathrm{v}}$ and $\sigma_{\mathrm{v}}^{2}$ can be obtained by simulation. An important result is that the asymptotic distribution is in this case free of nuisance parameters. Also, the $\mathrm{LM}^{\mathrm{F}}$ test seems to be robust to heteroscedasticity. McCoskey and Kao (1998) study the small sample properties of these tests using Monte Carlo methods, and find that they perform better, in terms of power, for a large $\mathrm{T}$. Also, when $\mathrm{N}$ and $\mathrm{T}$ are very close (e.g. $\mathrm{N}=50, \mathrm{~T}=50$ ) and there is a negative moving average component, the LM-DOLS test has higher power compared to the LM-FM test.

Pedroni (1996) uses the fully modified OLS estimator to deal with the problems of asymptotic bias and nuisance parameter dependency, associated with cointegrating vector estimates in a single equation model, and tests the hypothesis of strong PPP for a panel of countries in the post Bretton Woods period. This implies that the variables should move one-to-one in the long run. The single equation model is: 


$$
y_{i t}=\alpha_{i}+\beta x_{i t}+\mu_{i t}
$$

where $\mathrm{y}_{\text {it }}$ is the $\log$ U.S. nominal exchange rate, and $\mathrm{x}_{\mathrm{it}}$ is the $\log$ aggregate price ratio between the two countries in terms of the CPI, and strong PPP implies one-to-one adjustment in the long run. ${ }^{19}$

Pedroni (1997) proposes seven different panel cointegration tests. The construction of such tests is complicated, because the residuals may depend on the distribution of the estimated coefficients. He allows for considerable heterogeneity in the panel. In fact, he assumes a heterogeneous slope coefficient, fixed effects and individual specific deterministic trends. The model considered is a more general one than the model given by (25):

$$
\begin{array}{ll}
y_{i t}=\alpha_{i}+\delta_{i} t+\beta_{i} x_{i, t}^{\prime}+e_{i, t} & \begin{array}{l}
\mathrm{t}=1,2 \ldots \mathrm{T} ; \mathrm{i}=1, \ldots, \mathrm{N} \\
\mathrm{m}=1, \ldots \mathrm{M}
\end{array}
\end{array}
$$

where $\beta_{i}=\left(\beta_{1 i}, \beta_{21}, \ldots, \beta_{M i}\right)^{\prime}, \quad x_{i}=\left(x_{1 i t}, x_{2 i t}, \ldots, x_{M i i t}\right)^{\prime}, \mathrm{T}$ refers to the number of observations over time, $\mathrm{N}$ to the number of countries in the panel, and $\mathrm{M}$ to the number of regressors.

An important assumption discussed by Pedroni (1997) concerns the crossmember panel-wide properties of the data. Specifically, he assumes the idiosyncratic error terms to be independent across individual members of the panel, and proposes a GLS-based correction to allow for feedback across individual members of the panel. Of his seven tests, four are based on a within-dimension approach, and three on a between-dimension approach. In the first group we take the sum of both the numerator and the denominator terms over the $\mathrm{N}$ dimension. In the second group, we divide the numerator by the denominator prior to summing over the $\mathrm{N}$ dimension. We shall describe the construction of the seventh test, which is a parametric one.

\footnotetext{
${ }^{19}$ Pedroni (1996) tests the null hypothesis $\mathrm{H}_{0}: \beta_{\mathrm{i}}=1$ and finds evidence supporting weak but not strong PPP. One of the most recent papers using cointegration methods to test PPP is due to Canzoneri et al. (1999). They use traded goods prices, the German mark as the numeraire currency and the panel cointegration test proposed by Pedroni (1996), finding support for long-run PPP.
} 
1) Estimate the panel cointegration regression (30) and retrieve the residuals $e_{i, t}^{*}$

2) Run the panel regression in first differences: $\Delta y_{i, t}=\beta^{\prime}{ }_{i} \Delta x_{i, t}+\eta_{i, t} \quad \mathrm{t}=1,2 \ldots, \mathrm{T}$; $\mathrm{i}=1, . . \mathrm{N}$ and compute the residuals.

3) Calculate the long-run variance of $\eta^{*}, L_{11 i}^{* 2}=\Omega_{11 i}^{*}-\Omega_{21 i}^{*} \Omega_{22 i}^{*-1} \Omega_{21 i}^{* !}$

4) Using the residuals $\mathrm{e}^{*}{ }_{\mathrm{it}}$, estimate $e_{i, t}^{*}=\gamma_{i}^{*} e_{i, t-1}^{*}+\sum_{K=1}^{K i} \gamma_{i, k}^{*} \Delta e_{i, t-k}^{*}+\mu_{i, t}^{*}$ and use the residuals to compute the sample variance of $\mu_{i t}^{*}$ denoted by $s_{i}^{* 2}$.

The panel t-statistic is then defined as follows:

$$
N^{-1 / 2} Z_{t N, T}^{*}=N^{-1 / 2} \sum_{i=1}^{N}\left(\sum_{t=1}^{T} s_{i}^{* 2} e_{i, t-1}^{* 2}\right)^{-1 / 2} \sum_{t=1}^{T} e_{i, t-1}^{*} \Delta e_{i, t}^{*}
$$

This statistic can be viewed as analogous to the LL panel unit root test statistic applied to the estimated residuals of a cointegration regression. Let $z_{i t}=\left(y_{i t}, x_{i t}\right)^{\prime}$ be such that the process $z_{i t}$ is generated by $z_{i t}=z_{i, t-1}+\varsigma_{i t}$, for $\varsigma_{i t}=\left(\varsigma_{i t}^{y}, \varsigma_{i t}^{x}\right)^{\prime}$. Assume that the process $\varsigma_{i t}=\left(\varsigma_{i t}^{y}, \varsigma_{i t}^{x}\right)^{\prime}$ can be characterised in terms of standard Brownian motion. In this case, all we need to determine the complete distribution of the process above is its covariance structure $\Omega_{\mathrm{i}}$ (i.e., only the first two moments of the process). Also, assume that the error terms are independent across individual members of the panel. Under these two assumptions, the central limit theorem holds for each individual series as $\mathrm{T}$ grows large. The statistic described above can subsequently be standardised, relying on the moments of the Brownian motion function. If we denote with $\Theta^{*}$ and $\Psi^{*}$ the vector of means and the covariance matrix, its asymptotic distribution is given by $\mathrm{N}^{-1 / 2} \mathrm{Z}_{\mathrm{t}, \mathrm{N}, \mathrm{T}}-\Theta^{*}{ }_{2} \sqrt{N} \Rightarrow \mathrm{N}\left(0, \Psi^{*}{ }_{22}\right)$. This is an important result, as it tells us that the standardised statistic converges to a normal distribution whose moments depend on $\Psi^{*}$ and $\Theta^{*}$.

These moments ${ }^{20}$ can be obtained by Monte Carlo simulation and used to rewrite the asymptotic distribution as follows:

\footnotetext{
${ }^{20}$ Note that, although the statistics, under appropriate standardisation, converge to a normal distribution, there is no formal proof that the moments of the distribution are finite for each $\mathrm{N}, \mathrm{T}$. This technical difficulty also arises in the case of the t-bar test.
} 


$$
\frac{k_{N, T}-u \sqrt{N}}{\sqrt{v}} \Rightarrow N(0,1)
$$

where $k_{N, T}$ is the panel cointegration statistic, and $\mathrm{u}$ and $v$ are functions of the moments of the Brownian function.

Pedroni (1997) performs Monte Carlo simulations to study the small sample (power and size) properties of these seven statistics. He finds that the size distortions for all the proposed panel cointegration statistics are small, provided that there is not a negative moving average component in the DGP. Also, size distortions are small for $\mathrm{T}=250$ and larger for a smaller $\mathrm{T}$. Further, the power of the panel cointegration statistics is very high when $\mathrm{T}=100$ and $\mathrm{T}=250$. In brief, in terms of size distortion, the panel-rho statistic seems to exhibit the least distortions among the seven statistics. The group ADF exhibits the largest size distortions. In terms of power, the group ADF does very well, followed by the panel ADF and the panel-rho ${ }^{21}$.

All the panel cointegration tests presented above are residual-based, and do not allow for the possibility of multiple cointegrating vectors. Larsson et al (2001) address this issue, and propose a likelihood-based test of the cointegrating rank in heterogeneous panels. Assume that the data generating process for each of the groups is represented by the following $\operatorname{VAR}\left(\mathrm{k}_{\mathrm{i}}\right)^{22}$ :

$$
y_{i t}=\sum_{k=1}^{k_{i}} \prod_{i k} y_{i, t-k}+\varepsilon_{i t} \quad \mathrm{i}=1, \ldots, \mathrm{N}
$$

As shown by Engle and Granger (1987), the corresponding error correction representation is the following:

$$
\Delta y_{i t}=\Pi_{i} y_{i, t-1}+\sum_{k=1}^{k i} \Gamma_{i k} \Delta y_{i, t-k}+\varepsilon_{i t} \quad \mathrm{i}=1, \ldots \mathrm{N}
$$

\footnotetext{
${ }^{21}$ Cerrato and Sarantis (2002) use the seven panel cointegration tests suggested by Pedroni (1997) to test for cointegration in a trivariate PPP framework using monthly nominal exchange rates and a panel of twenty OECD countries. After testing for the validity of the joint symmetry and proportionality restrictions, they conclude that unit root tests of the real exchange rate may be biased towards finding no evidence of PPP. Panel tests, though more supportive of PPP, still produce mixed results.

${ }^{22}$ In what follows, one may think of $y_{i t}$ as being the real exchange rate.
} 
where $\Pi_{i}$ is of order $p \times p$ ( $p$ being the number of variables in each group). The matrix $\Pi_{\mathrm{i}}$ can be decomposed into $\Pi_{\mathrm{i}}=\alpha_{i} \beta_{i}{ }^{\prime}$, where $\alpha_{\mathrm{i}}$ and $\beta_{\mathrm{i}}$ are matrices of order $\mathrm{p} \times$ $r_{i}$ representing the long-run coefficients and the adjustment parameters respectively. Consider the following null and alternative hypotheses:

$$
\begin{aligned}
& H(r): \operatorname{rank}(\Pi) \leq r \\
& H(p): \operatorname{rank}(\Pi)=p
\end{aligned}
$$

As in Johansen (1988), the likelihood ratio test (the trace statistic) ${ }^{23}$ can then be written as follows:

$$
-T \sum_{i=r+1}^{p} \ln \left(1-\lambda_{i}^{*}\right)=-2 \ln Q_{T}(H(r) ! H(p))
$$

Since we are interested in testing the hypothesis that all $\mathrm{N}$ groups in the panel have the same number of cointegrating relationship $\left(\mathrm{r}=\mathrm{r}_{\mathrm{i}}\right)$, the null and the alternative can be specified as:

$$
\begin{aligned}
& H_{0}: \operatorname{rank}\left(\Pi_{i}\right)=r_{i} \leq r \quad \text { for all } i=1 \ldots N \\
& H(p): \operatorname{rank}\left(\Pi_{i}\right)=p \quad \text { for all } i=1 \ldots N
\end{aligned}
$$

The LR-bar statistic can be defined as the average of the $\mathrm{N}$ individual trace statistics $\operatorname{LR}_{\mathrm{iT}}\left(\mathrm{H}(\mathrm{r}){ }_{\mid}^{\prime} \mathrm{H}((\mathrm{p})):{ }^{24}\right.$

$$
L R_{N T}(H(r) ! H(p))=1 / N \sum_{i=1}^{N} L R_{i T}(H(r) ! H(p))
$$

Using a standardisation procedure, one obtains the standardised LR-bar statistic for panel cointegration:

\footnotetext{
${ }^{23}$ Note that the trace statistic refers to each group $i$.
} 


$$
\gamma_{L R-\operatorname{bar}}(H(r) ! H(p))=\frac{\sqrt{N}\left(L R_{N T}(H(r) ! H(p))-E\left(Z_{K}\right)\right)}{\sqrt{\operatorname{Var}\left(Z_{k}\right)}}
$$

where $E\left(Z_{K}\right)$ and $\operatorname{Var}\left(Z_{K}\right)$ are the mean and variance of the asymptotic trace statistic.

The original contribution made by Larsson et al (2001) is to show that every study performed in a non-panel context can be extended to a panel framework. Furthermore, by proposing the panel data analogue of the Johansen maximum likelihood method, they are able to study the case of multiple cointegrating vectors in panels ${ }^{25}$.

In Larsson et al (2001) a common cointegrating rank is simply assumed. Larsson and Lyhagen (2000) suggest the following way to test this hypothesis. First, the LR-bar statistic of Larsson et al (2001) is applied to obtain the maximum rank amongst the $\mathrm{N}$ individual ones. Then, a panel test (PC-bar) is implemented to test the hypothesis of $\mathrm{r}$ cointegrating vectors against $\mathrm{r}-1$. This is based on the test proposed by Harris (1997). If the two tests coincide, the null of the same number of cointegrating relations cannot be rejected, otherwise the null hypothesis is rejected and the alternative is accepted.

Larsson and Lyhagen (1999) derive two test statistics in the context of a panelVAR with cointegrating restrictions: a likelihood ratio test for the cointegrating rank, and another for a common cointegrating space. Let $\mathrm{i}=1, \ldots \mathrm{N}$ be the index for the groups, $\mathrm{t}=1, \ldots \mathrm{T}$ the sample time period and $\mathrm{j}=1, \ldots \mathrm{p}$ the variables in each group, with $\mathrm{y}_{\mathrm{ijt}}$ denoting the ith group, jth variable at time t. Consider the following model:

$$
\Delta y_{t}=\pi y_{t-1}+\sum_{k=1}^{m-1} \Gamma_{k} \Delta y_{t-k}+s_{t}
$$

where $y_{t}=\left(\mathbf{y}_{1 t}^{\xi}, \mathbf{y}_{2 t}^{\xi}, \ldots \mathbf{y}_{\mathrm{Nt}}^{\xi}\right)^{\xi}$ is the Nxp vector of the panel of observations available at time $t$ on the $\mathrm{p}$ variables for the $\mathrm{N}$ groups, and $\varsigma=\left(\varsigma^{\xi} 1 \mathrm{t}, \ldots \varsigma^{\xi} \mathrm{Nt}\right)^{\xi}$ with $\varsigma^{\sim} \mathrm{N}(0, \Omega) . \pi$ and $\Gamma$ can be divided into submatrices $\pi_{\mathrm{ij}}$ and $\Gamma_{\mathrm{ij}} \mathrm{i}, \mathrm{j}=1, \ldots \mathrm{N}$.

\footnotetext{
${ }^{24}$ This test is based on the approach suggested by Im et al (1997) for the univariate unit root panel test statistic.

${ }^{25}$ Cerrato and Sarantis (2002) apply the Larsson et al (2001) tests in a trivariate PPP framework using a panel of twenty monthly nominal exchange rates, and report strong evidence of cointegration.
} 
Since the rank of $\pi$ is $\Sigma r_{i}$, where $0 \leq r_{i} \leq p$, we can write $\pi$ as $\pi=A B^{\xi}$, where A and $\mathrm{B}$ are two matrices of order $\mathrm{Np} \times \Sigma \mathrm{r}_{\mathrm{i}}$, with A containing the short-run coefficients

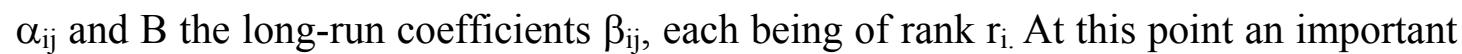
restriction is discussed by Larsson and Lyhagen (1999). They assume that $\beta_{\mathrm{ij}}=0$ but $\alpha_{\mathrm{ij}} \neq 0$. In this way, the model allows short-run, but not long-run dependence between the panel groups. The off-diagonal elements in $\pi=A B^{\prime}$, that is $\pi_{i j}=\alpha_{i j} \beta_{j}{ }^{\prime}$, represent the short-run dependencies of the changes in the series for group $i$ due to long-run equilibrium deviations in group j. These assumptions enable Larsson and Lyhagen (1999) to re-write the model (38) in the following form:

$$
\Delta y_{t}=A B^{\prime} y_{t-1}+\sum_{k=1}^{m-1} \Gamma_{k} \Delta y_{t-k}+\varsigma_{t}
$$

Given the model and two homogeneity restrictions, $B=\operatorname{Diag}\left(\beta_{i i}\right)$ and $B=\left(I_{N} \otimes \beta\right)$, model $\mathrm{B}=\left(\mathrm{I}_{\mathrm{N}} \otimes \beta\right)$ is tested against $\mathrm{B}=\operatorname{Diag}\left(\beta_{\mathrm{ii}}\right)$. The distribution of the test for the cointegrating rank and for a common cointegrating space are shown respectively to be equal to the convolution of a Dickey-Fuller type distribution and an independent $\chi^{2}$ variate, and a $\chi^{2}$ distribution, with the number of degree of freedom given by $(\mathrm{N}$ 1)r(p-r).

\subsection{An Empirical Example}

In this subsection we apply some of the panel cointegration tests described above; in particular, we focus on heterogeneous panel cointegration, that is, the seven panel tests proposed by Pedroni (1997) and the Larsson et al (2001) test. We use a trivariate PPP framework without imposing any a-priori symmetry restriction. The results of the Pedroni test are reported in Table 2: 
Table 2

\begin{tabular}{|lc|}
\hline Pedroni (1997) Panel Cointegration tests \\
Panel v-Statistic & 2.12611 \\
Panel rho-statistic & 0.48956 \\
Panel pp-statistic & 0.34276 \\
Panel ADF-statistic & 0.83774 \\
Group Rho-statistic & 1.6804 \\
Group pp-statistic & 1.68045 \\
Group ADF-statistic & 2.2638 \\
\hline
\end{tabular}

The Pedroni (1997) panel cointegration tests cannot reject the null hypothesis of no cointegration, with the exception of the panel v-statistic, implying little evidence in favour of PPP. Note that the Pedroni (1997) statistics have critical values of -1.64 ( $k<1.64$ suggests a rejection of the null). The $v$ statistic has a critical value of 1.64 ( $k>1.64$ suggesting a rejection of the null). Means and variances used to calculate these statistics are from Pedroni (1999, Table 2), with heterogeneous intercepts included. The results for the Larsson et al (2001) test are reported in Table 3. This test relies on combining N-trace statistics.

Table 3

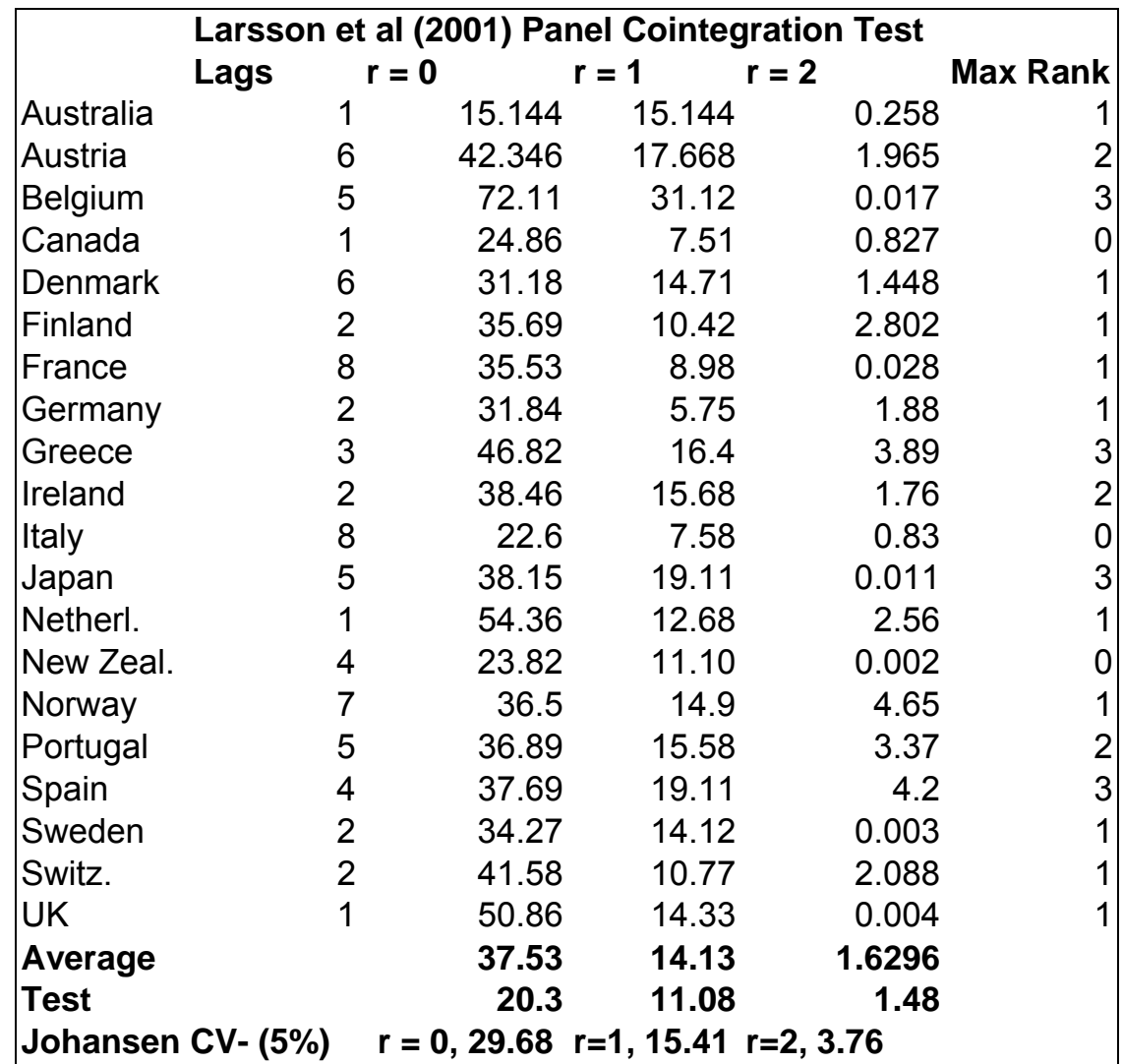


The individual trace statistics indicate that for most of the countries in our panel the maximum rank is 1. In the case of Spain, Japan, Greece and Belgium it is found to be three. The trace test implies no cointegration in only three cases, i.e. Canada, Italy and New Zealand. The Larsson et al (2001) test statistic is reported at the bottom of the table. It has been computed using equation (37) with mean and variance obtained from Larsson et al (2001). Since the test follows a normal distribution its $5 \%$ critical value is 1.645. It suggests that there exist two cointegrating vectors between the nominal exchange rate, domestic prices and foreign prices.

This example illustrates clearly that, when carrying out panel cointegration tests of PPP, one should (a) allow for heterogeneity when testing for cointegration between the nominal exchange rate, domestic and foreign prices, and (b) avoid apriori restrictions such as symmetry restriction.

\section{Some Unresolved Issues in Panel Unit Root and Cointegration Tests}

Despite the considerable progress made in the area of panel data econometrics, several unresolved problems remain. For instance, there is extensive Monte Carlo evidence indicating size distortions and low power in the commonly used unit root tests $^{26}$. The empirical distribution of these tests is very different from the asymptotic one in the presence of negative moving average errors. In this case, the implementation of unit root tests often necessitates a large autoregressive truncation lag (k). Monte Carlo simulations have demonstrated an association between $\mathrm{k}$ and the severity of size distortion ${ }^{27}$ ( $\mathrm{Ng}$ and Perron, 1999). If the moving average components are small, a small $\mathrm{k}$ is adequate. On the other hand, if they are large, a large value of $\mathrm{k}$ is required. However, such a strategy may not be feasible, since selecting a large $\mathrm{k}$ may lead to overparameterisation and a consequent loss of power. The difficulty with the most common methods for selecting a value of $\mathrm{k}$, i.e. the Akaike Information Criterion (AIC) and the Schwarz Information Criterion (SIC), is that they tend to select a value of $\mathrm{k}$ which is too small. The bias in the estimated sum of the

\footnotetext{
${ }^{26}$ The two problems should be kept distinct (see Ng and Perron, 1999). Low power arises when the dominant root is near, but not exactly equal to, unity. Size distortion may arise, for example, when the underlying distribution contains a negative moving average component. However, in panel data, size distortion may also arise from cross-sectional dependence.

${ }^{27}$ Simulations for $\mathrm{T}=100$ and 250 have provided evidence that the size issue in the negative moving average case is not a small sample problem. In this case, the consequence is overrejection of the unit root hypothesis ( $\mathrm{Ng}$ and Perron, 1999).
} 
autoregressive coefficients $\left(\beta^{*}\right)$ might depend on $\mathrm{k}$ in the presence of a negative moving average component. To see the problem, assume the following data generating process (DGP):

$$
\begin{aligned}
& y_{t}=d_{t}+u_{t} \\
& \mathrm{~d}_{\mathrm{t}}=\varphi^{\prime} \mathrm{z}_{\mathrm{t}}
\end{aligned}
$$

where $\mathrm{z}_{\mathrm{t}}$ is a set of deterministic components

$$
\begin{aligned}
& u_{t}=\alpha u_{t-1}+v_{t} \\
& v_{t}=e_{t}+\phi e_{t-1}
\end{aligned}
$$

The Dickey-Fuller test (1979) is the t-statistic for $\beta_{0}$ in the autoregression:

$$
\Delta y_{t}=d_{t}+\beta_{0} y_{t-1}+\sum_{j=1}^{k} \beta_{j} \Delta y_{t-j}+u_{t k}
$$

The AIC or the SIC methods for selecting $\mathrm{k}$ belong to the class of informationbased criteria (IC) where the value of $\mathrm{k}$ is $\mathrm{k}_{\mathrm{ic}}=\arg$. $\min _{\mathrm{k}} \mathrm{IC}(\mathrm{k})$ :

$$
\mathrm{IC}(\mathrm{k})=\log \left(\delta_{\mathrm{k}}^{* 2}\right)+(\mathrm{k}) \mathrm{C}_{\mathrm{t}} / \mathrm{T}
$$

with $\delta_{k}^{* 2}=T^{-1} \sum_{t=k+1}^{T} u_{t k}^{2^{*}}, \mathrm{C}_{\mathrm{t}} / \mathrm{T} \rightarrow 0$ as $\mathrm{T} \rightarrow \infty$ and $\mathrm{C}_{\mathrm{t}}>0$, where $\mathrm{C}_{\mathrm{t}}$ is the weight applied to overfitting.

We select $\mathrm{k}^{*}$ such that $\lim _{\mathrm{t} \rightarrow \infty} \mathrm{E}\left(\mathrm{T}\left(\mathrm{k}-\mathrm{k}^{*}\right)\right)=0$, i.e. to minimise the objective function (43) (see Gourieroux and Monfort, 1995). However, this method does not allow for the possibility that the bias in the estimated sum of the autoregressive coefficients:

$$
\pi_{T}(k)=\left(\delta_{k}^{* 2}\right)^{-1} \beta_{0}^{* 2} \sum_{t=k+1}^{T} y_{t-1}^{* 2}
$$


might depend on $\mathrm{k}$ in the presence of a negative moving average component. The reason is that this bias is very high for small values of $\mathrm{k}$, and, unless $\mathrm{k}$ is very large, it persists and becomes highly dependent on $\mathrm{k} .{ }^{28}$ Based on this evidence, $\mathrm{Ng}$ and Perron (2001) show that the modified Akaike information criterion (MAIC) gives the best combination of size and power ${ }^{29}$.

Another very important issue in panel unit root and cointegration tests is the structure of the covariance matrix, which is generally assumed to be diagonal. As pointed out by Im et al (1997), this requires the observations to be generated independently across different groups, that is, no cross-sectional dependence. There are currently two strands of the literature dealing with a non-diagonal covariance matrix. The first has focused mainly on the correlation between group of observations (i.e. cross-sectional dependence), the second on group dependence in the innovations. As we shall stress below, in general the two are closely related.

Panel data refers to the pooling of observations on a cross-section of households, countries, firms, over several time periods. This can be achieved by surveying a number of households or individuals and following them over time. We obtain a combination of time series and cross-section data. But why should one be concerned with cross-sectional dependence? Recall that the properties of all the tests described before are based on the assumption that data in one group are generated independently from those in another group - in other words, that there is no dependence between different groups of observations. Provided that this assumption holds, one can use the central limit theorem and derive the asymptotic distribution for

\footnotetext{
${ }^{28}$ Different methods have been suggested to deal with this problem. For example, Carner and Kilian (1999) report extreme size distortions for the Leybourne and McCabe (1994) test and the KPSS test. They consider a highly persistent model under the null of stationarity, and a unit root process under the alternative. They overcome the size distortions using appropriately adjusted finite sample critical values, and demonstrate that such corrections inevitably result in a dramatic loss of power in the tests. However, these results should be interpreted with caution, as the DGP assumed is an $\operatorname{AR}(1)$ process with root $\rho$ and NID $(0,1)$ innovations. Furthermore, the number of lagged terms (l) is selected using a procedure for a fixed 1 as a function of $\mathrm{T}$, i.e. $\mathrm{l}=$ int $\left(\mathrm{C}(\mathrm{T} / 100)^{1 / \mathrm{d}}\right)$ with $\mathrm{c}=12$ and $\mathrm{d}=4$, which might lead to overparameterisation and loss of power. Furthermore, the finite sample critical values are derived from a parametric model, which clearly violates the nonparametric spirit of the KPSS test.

${ }^{29}$ Recently Lopez et al (2002) report evidence suggesting that the MAIC criterion works well with DF-GLS tests, but for ADF tests the Campbell and Perron (1997) method is preferable.
} 
a particular panel estimator ${ }^{30}$. There are different kinds of cross-sectional correlation: homogeneous, quasi heterogeneous and heterogeneous. Consider, for instance, the relationship between the Swiss and UK real exchange rates, where the US dollar is used as the numeraire currency. The two will be correlated, as by construction they contain two common elements, i.e. the independent variation in the value of the dollar and in the US price index (O`Connell, 1998). Consider the following real exchange rate model:

$$
\begin{aligned}
& \Delta q_{i, t}=\beta_{i} q_{i, t-1}+u_{i, t} \\
& u_{i, t}=\theta_{t}+\varepsilon_{i, t}
\end{aligned}
$$

where $\theta_{\mathrm{t}}$ is a stationary time-specific common effect across groups, and $\mathrm{q}_{\mathrm{t}}$ is the real exchange rate (and the US dollar is the numeraire currency).

The effect of the omitted global variable is, as shown by (46), entirely captured by innovations. Equation (46) assumes a homogeneous form of crosssectional dependence, as the dependence induced by the independent variation in the value of the US dollar and price index is the same for all exchange rates, and, therefore, the covariance matrix of the innovations can be assumed to be of the following type (see O`Connell, 1998):

$$
\Omega=\left[\begin{array}{cccc}
1 & \omega & \ldots & \omega \\
\omega & 1 & \ldots & \omega \\
\cdot & . & . & . \\
\omega & \omega & \ldots & 1
\end{array}\right] \quad \omega<1
$$

where $\omega$ is the contemporaneous correlation between real exchange rate innovations ${ }^{31}$.

If the covariance matrix is not diagonal, we can correct the bias by subtracting the cross-sectional means from the observed series. This is the procedure suggested

\footnotetext{
${ }^{30}$ Note that, in extremis, one could still use the central limit theorem in the case of dependent random variables; however, this would require a finite variance to establish convergence (see, for example, White, 2001).

${ }^{31}$ Note that, as equations 50 and 51 show, it is the correlation between the Swiss and UK real exchange rates that causes between-group dependence in the innovations and a non-diagonal covariance matrix (see equation 52).
} 
by Im et al (1997), ${ }^{32}$ which can be summarised in the following way. Consider the following DGP for the real exchange rate $q_{i t}$ :

$$
q_{i, t}=\beta_{i} q_{i t-1}+u_{i, t} \quad i=1, \ldots, N \quad t=1, \ldots, T
$$

Equation (48) consists of $\mathrm{i}$ countries observed t times. It is convenient for our purposes to stack (48) into $\mathrm{N}$ equations as follows:

$$
q_{t}=\beta q_{t-1}+u_{t}
$$

with each of the $\mathrm{N}$ equations consisting of $\mathrm{T}$ observations.

Define by $i^{\prime}=[1, \ldots, 1]$ a vector that contains columns of ones. Then $i i^{\prime}=N \times N$. Also, define the covariance matrix as $\Omega=E\left(u_{t} u_{t}^{\prime}\right)$. Finally, consider two different cases for $\Omega$. In the first the covariance matrix is assumed to be diagonal, whilst in the second it takes the form given in (47). By using the demeaning procedure the covariance matrix reduces to:

$$
\Omega=\left(u_{t}-u_{t}^{A V}\right)\left(u_{t}-u_{t}^{A V}\right)^{\prime} \text { where } u_{t}^{A V} \text { is the average of } u_{t}
$$

Define the following idempotent symmetric matrix $P=I-\frac{1}{N} i i^{\prime}$ and $i^{\prime}=[1, . ., 1]$

$$
P_{N \times N}=\left(\begin{array}{rrrr}
1-\frac{1}{N} & -\frac{1}{N} & -\frac{1}{N} & -\frac{1}{N} \\
& 1-\frac{1}{N} & -\frac{1}{N} & -\frac{1}{N} \\
& & 1-\frac{1}{N} & -\frac{1}{N} \\
& & 1-\frac{1}{N}
\end{array}\right)
$$

\footnotetext{
${ }^{32}$ Under these assumptions, and if cross-sectional dependence is of a weak-memory variety, the central limit theorem may still apply. However, when there are strong correlations in a cross-section (as there will be in the presence of global shocks), we may expect it to fail (see Phillips and Moon, 1999).
} 
Using the general expression of the covariance given above and (51), we obtain:

$$
\begin{aligned}
& P u_{t}\left(P u_{t}\right)^{\prime}=\Omega^{*} \\
& \Omega^{*}=P u_{t} u_{t}^{\prime} P^{\prime} \\
& \Omega^{*}=P \Omega P^{\prime}
\end{aligned}
$$

Equation (52) represents the covariance matrix after the demeaning procedure. It is straightforward to see that it is no longer diagonal. This result is not surprising since it is the subtracting of the cross-sectional means that determines cross-sectional dependence: we are subtracting a common element (same information) from each cross-unit ${ }^{33}$.

Let us consider the case when the covariance matrix is not diagonal and of the form given in $(47)^{34}$. By using (47) in conjunction with (51) we have:

$$
\begin{aligned}
& \Omega=(1-\omega) I+\omega i i^{\prime} \\
& P \Omega P^{\prime}=\left(I-\frac{1}{N} i i^{\prime}\right)\left[(1-\omega) I+\omega i i^{\prime}\right] P
\end{aligned}
$$

which after some algebra reduces to:

$$
P \Omega P^{\prime}=(1-\omega) P
$$

It is clear from (54) that, in the presence of cross-sectional dependence, the covariance matrix depends on the parameter $\omega$ that measures its degree. The

\footnotetext{
${ }^{33}$ By doing so, we may lose important information. One solution is to model the cause of dependence between groups of innovations.

${ }^{34}$ Note that we are considering only a limited case of cross-sectional dependence, i.e. of a homogeneous type. Modelling the covariance matrix in the case of heterogeneity is much more complicated.
} 
demeaning procedure is not effective even for very large N. In fact, as $N \rightarrow \infty$, the parameter $\omega$ still appears in equation $(54)^{35}$.

The type of correlation considered above assumes that the degree of dependence is the same for all groups of observations (i.e. homogeneous crosssectional dependence). But in many cases units might respond in different ways to global shocks. In the extreme case, some units may not be affected at all. Then, as shown by O`Connell (1998), equation (50) becomes:

$$
u_{i, t}=r_{i} \theta_{t}+\varepsilon_{i, t}
$$

The covariance matrix that describes the correlation between real exchange rate innovations is still not diagonal, but now it is also heterogeneous. This is a form of heterogeneous cross-sectional correlation (see Maddala and $\mathrm{Wu}, 1999$, and Higgings and Zakrajsek, 2000). For example, between any two countries (and real exchange rates), in addition to the base currency effect, there might be other sources of correlation between real exchange rate innovations, that is generated by exogenous global shocks.

One solution is to use GLS-based corrections as proposed by Pedroni (1999) and O'Connell (1998). This produces an estimator with critical values invariant to cross-sectional correlation. An alternative solution is to use bootstrap methods to obtain the empirical distributions of the test statistics for the purpose of statistical inference (Maddala and $\mathrm{Wu}, 1999)$. The problem with the use of feasible GLS (FGLS) techniques to deal with cross-sectional dependence is that they generally require the imposition of a homogeneous serial correlation structure (the autoregressive parameter is assumed to be the same across i) and the selection of the same lag length, as in O'Connell (1998), and Higgins and Zakrajsek (2000). This is too restrictive for two reasons. First, if the serial correlation pattern is heterogeneous the invariance property of FGLS breaks down. Second, the selection of the same lag length, generally, is not supported empirically (see Papell and Theodoridis, 2000).

\footnotetext{
${ }^{35}$ Note that, if we were able to model $\omega$ by filtering the effect of the unobservable factor $\theta_{t}$, we could make equation (54) free from the nuisance parameter $\omega$. This is, broadly speaking, the approach suggested in Pesaran (2003) where heterogeneous cross-sectional dependence is considered. However, this method might dependent on the particular structure assumed for the covariance matrix of $\xi_{i t}=\varepsilon_{i t}-\delta_{i} \bar{\varepsilon}_{t}$
} 
Furthermore, the consistence of the FGLS estimator relies on that of the estimator used to estimate the covariance matrix. Usually, the latter is the Pooled Least Square Estimator (POLS). Coakley et al (2002) show that, under cross-sectional dependence, this estimator is inconsistent ${ }^{36}$.

Another strand of literature has preferred to focus on between-group correlation of innovations. In fact, we could have a situation where a non-diagonal covariance matrix arises from the omission of a variable that is completely uncorrelated with the included regressors. In other words, there might be no correlations between different groups of observations, but because the effect of the omitted variable is captured by the innovations, the covariance matrix will not be diagonal. SURE procedures have been recommended in this case. The logic behind such an approach is that, since the efficiency of the SURE estimator increases with the degree of correlation between the innovations, relative to correlation between groups of observations, one should gain in efficiency by using it. However, since the SURE approach in panels consists in a multivariate FGLS procedure, all the drawbacks highlighted above are also relevant here. Furthermore, if the cause of a non-zero diagonal covariance matrix is the omission of a global variable that is correlated with the included regressors (that is, if we have cross- sectional dependence), then the SURE estimator is not necessarily superior to the OLS estimator (see Maddala, 2002).

Recently, Banerjee et al (2001) noted another source of size distortion in panel unit root and cointegration tests in addition to cross-sectional dependence, namely the presence of cointegration between different groups. ${ }^{37}$ They perform Monte Carlo simulations showing that this is the case for some of the most common panel unit root and cointegration tests (i.e. LL, 1993, Im et al, 1997 and Maddala and Wu, 1999) ${ }^{38}$. The panel unit root test that suffers the least from size distortion is the LL2 (1993) one. The implication for applied work is the same as in the presence of cross-

\footnotetext{
${ }^{36}$ Phillips and Soul (2003) also show that, under cross-sectional dependence, both the POLS and the FGLS estimators are biased. However, we can always estimate the covariance matrix by using a non-parametric approach.

${ }^{37}$ Cross-cointegration can be viewed as long-run cross-correlation between different groups. It could be due, for example, to a common stochastic trend driving different groups, and as such it has been analysed by Bai and $\mathrm{Ng}$ (2002a), and Larsson and Lyhagen (2000).

${ }^{38}$ Lyhagen (2000) also studies the size of different panel unit root and cointegration tests in the presence of cointegration across units. He finds the McCoskey and Kao (1998) test to perform better than the Im et al (1997) under these circumstances.
} 
sectional dependence, that is, the null hypothesis is rejected too often. However, the Monte Carlo experiments conducted by Banerjee et al (2001) might be biased in favour of the LL test. In fact, their Monte Carlo experiments are entirely calibrated on the LL test ${ }^{39}$. Consequently, it is not surprising that the LL test should be found to perform better than the others in the presence of cointegration between groups: this result might simply reflect the Monte Carlo design. Furthermore, they compare tests based on different hypotheses. Recall that the Im et al (1997) test is a heterogeneous test where the alternative is that some units are stationary while some others are not. On the other hand, the LL is a homogeneous test with the alternative that all units are stationary. This comparison between tests testing different hypotheses might not be entirely appropriate after-all.

\section{Conclusions}

This paper provides a critical overview of the major panel unit root/cointegration tests used in the literature to test long-run PPP. We have outlined the unit root tests introduced by Levin and Lin (1993), Im et al (1997), Taylor and Sarno (1998) and Maddala and $\mathrm{Wu}$ (1999) and highlighted their limitations. We have also discussed some panel cointegration tests such as the ones proposed by Larsson et al (2001), Pedroni (1997) and McCoskey and Kao (1998). We have considered (i) the role of $\mathrm{ADF}$ regressions as a way of allowing for serially dependent and heteroscedastic residual processes; (ii) the problem of heterogeneity in panel unit root and cointegration tests and its implication for applied work on PPP; (iii) the problem of endogeneity in cointegration tests; (iv) the low power and size distortion of unit root tests in the presence of a negative moving average component. An important common feature of all of the tests presented in this survey is that their asymptotic distributions were derived under the assumption of no correlation between groups of observations, which implies a diagonal covariance matrix. We have pointed out that this assumption is often violated, and therefore the asymptotic distributions of panel estimators may no longer be reliable. Different approaches have been suggested in the literature to deal with cross-sectional dependence and a non-diagonal covariance matrix. However, further investigation is still required.

\footnotetext{
${ }^{39}$ They adopt exactly the same Monte Carlo design as in Levin and Lin, 1993.
} 
The main lessons to be learned from this overview can be summarised as follows. First, size distortion in panel unit root tests increases the likelihood of type-I errors. Panel tests that assume i.i.d. disturbances suffer from severe size biases, that is, the derived distributions are not valid and should not be used to draw statistical inference. FGLS or SURE techniques are unlikely to provide a solution to the problem. The assumption of a homogeneous slope parameter is too restrictive in many applied contexts, and in particular for testing PPP.

Researchers have used panel unit root tests to overcome the problem of the low power of the univariate unit root tests implemented in the early literature on PPP, and found stronger evidence supporting PPP, especially for German mark-based bilateral exchange rates, though the empirical findings are still mixed, and the issue of whether or not long-run PPP holds is yet to be settled conclusively. Very little work has been done using panel cointegration tests. Therefore, a final and relevant question to be asked is: are panel methods likely ever to solve the PPP puzzle? We believe that they might not provide the solution that was being sought by researchers. It is well known that most time series estimators (for instance, OLS) suffer from small sample bias. This is a serious problem in time series analysis, especially when estimating half-lives deviations of the real exchange rate from PPP (see Murray and Papell, 2002). Phillips and Soul (2003) show that in panels small sample bias and crosssectional dependence work jointly, that is one reinforces the other, in this way making inference in panels almost impossible. In other words, most of the typical problems we encounter in time series analysis are amplified in panel analysis, with the implication that it is even more difficult to obtain clear-cut results.

A more promising direction for future research on PPP might be to use nonlinear estimators. The importance of non-linearities in exchange rate modelling has become increasingly clear in recent years (see Taylor and Peel, 2000). Estimating non-linear models might at last provide more conclusive evidence, and explain the PPP puzzle without the need to wait for a much larger number of observations to become available, as required for standard linear estimators to have sufficiently high power. 


\section{References}

Bai, J., and $\mathrm{Ng}$, S., 2002a, "Determining the Number of Factors in Approximate Factor Models", Econometrica, 70, 191-221.

Bai, J., and Ng, S., 2002b, "A Panic Attack on Unit Roots and Cointegration", Department of Economics, Boston College, Unpublished Manuscript.

Banerjee, A., 1999, "Panel Data Unit Roots and Cointegration: An Overview", Oxford Bulletin of Economics and Statistics, 61, 607-629.

Banerjee, A., M. Marcellino and C. Osbat, 2001, "Testing PPP: Should We Use Panel Methods?" European University Institute, Working Papers.

Campbell, J. Y, and P., Perron, 1991, "Pitfalls and Opportunities: What Macroeconomists Should Know About Unit Roots" NBER, Macroeconomics Annals, Vol. 6, O.J. Blanchard and S. Fisher (eds.).

Carner, M. and Kilian, L., 1999, "Size Distortions of Tests of the Null Hypothesis of Stationary: Evidence and Implications for the PPP Debate". University of Michigan, Working Papers in Economics.

Canzoneri, B., M., Cumby, R., and B., Diba., 1999, "Relative Labour Productivity and the Real Exchange Rate in the Long-Run: Evidence for a Panel of OECD Countries". Journal of International Economics, 47, 245-266.

Cassell, G., 1918, "Abnormal Deviations in International Exchanges", Economic Journal, 413-415.

Cerrato, M., and N., Sarantis 2002, "Panel Cointegration Tests of Purchasing Power Parity", D.P. no. 02-4, Centre for International Capital Markets, London Metropolitan University.

Cerrato, M., and N., Sarantis, 2004, "Cross Sectional Dependence, Panel Unit Root Tests, and Purchasing Power Parity", D.P. no. 04-2, Centre for International Capital Markets, London Metropolitan University.

Coakley, J. and Fuertes, A.M., 1997, "A New Panel Unit Root Test of PPP" Economic Letters, 57, 17-22.

Coakley, J., and Fuertes, A.M, 2000, "Is There a Base Currency Effect in Long Run PPP?", International Journal of Finance and Economics, 5, 4, 253-263.

Coakley, J., A.,Fuertes and R., Smith, 2002, "A Principal Components Approach to Cross section Dependence in Panels". Birkbeck College, Economics Working Papers.

Dickey, D.A., and Wayne A., Fuller, 1979, "Distribution of the Estimators for Autoregressive Time Series with a Unit Root", Journal of the American Statistical Association, 74, 427-431.

Dickey, D.A., and Wayne A., Fuller, 1981, "Likelihood Ratio Statistics for Autoregressive Time Series with a Unit Root", Econometrica, 49, 1057-1072.

Enders, W., and Falk, B., 1998, "Threshold-Autoregressive, Median Unbiased, and Cointegration Tests of Purchasing Power Parity". International Journal of Forecasting, 14, 171-186.

Engle, R.F and C.W.J. Granger, 1987, "Co-integration and Error Correction: Representation, Estimation and Testing”, Econometrica, 55, 251-276.

Fisher, R.A, 1932, Statistical Methods for Research Workers, 4th ed, Oliver and Boyd, Edinburgh.

Frankel, J, A. and Rose, A., K., 1996, "A Panel Project on Purchasing Power Parity Within and Between Countries", Journal of International Economics, 40, 209224. 
Froot, K., A., and Rogoff, K., 1995, "Perspectives on PPP and Long-Run Real Exchange Rates, in Rogoff, K., and Grossman, G., (eds), Handbook of International Economics, Amsterdam: North Holland.

Gourieroux, C. and Monfort, A. 1995, Statistical and Econometric Models, Vol. 1, Cambridge University Press, Cambridge.

Hall, S.G. and G. Urga, 2000, "New Developments in the Analysis of Panel Data Sets", in S.B. Dahiya (ed.) The Current State of Business Disciplines, Vol.2 (Business Economics), Chapter 28, pp.537-564.

Harris, D., 1997, "Principal Component Analysis of Cointegrated Time Series", Econometric Theory, 13, 529-557

Harris, D., and E., Tzavalis, 1999, "Inference for Unit Roots in Dynamic Panels where the Time Dimension is Fixed", Journal of Econometrics, 91, 201-226

Higgins, M. Zakrajsek, E., 2000, "Purchasing Power Parity: Three Stakes Through the Heart of the Unit Root Null", Federal Reserve Bank of New York, Working Papers.

Im, K-S., Pesaran M.H and Shin Y., 1997, " Testing for Unit Roots in Heterogeneous Panels", WP 9526, DAE, University of Cambridge. Revised June 1997.

Johansen, S., 1988, "Statistical Analysis of Cointegration Vectors", Journal of Economic Dynamics and Control, 12, 231-254.

Karlsson, S., and M., Lothgren, 2000, "On the Power and Interpretation of Panel Unit Root tests", Economics Letters, 66, 249-255.

Koedijk, G., K et. al , 1998, “ The Re-emergence of PPP in the 1990s", Journal of International Money and Finance, 17, 51-61.

Koedijk, G., K., Schotman, P., C., 1990 "How to Beat the Random Walk: An Empirical Model of Real Exchange Rates". Journal of International Economics 29, 311-332.

Kwiatkowski, D., P.C.B. Phillips, P. Schmidt, and Y. Shin, 1992, “ Testing the Null Hypothesis of Stationarity against the Alternative of a Unit Root". Journal of Econometrics, 54, 159-178.

Larsson, J., Lyhagen and M., Lothgran, 2001, "Likelihood-Based Cointegration Tests in Heterogeneous Panels", Econometrics Journal, 4, 109-141.

Larsson, R and J., Lyhagen, 1999 " Likelihood Based Inference in Multivariate Panel cointegration Models", Working Papers Series in Economics and Finance No. 331, Stockholm School of Economics.

Larsson, R and J., Lyhagen, 2000, “ Testing for Common Cointegrating Rank in Dynamic Panel”, Working Papers Series in Economics and Finance No. 378, April 21, Stockholm School of Economics.

Leybourne, S. and McCabe, B. (1994). "A consistent test for a unit root," Journal of Business and Economic Statistics, 12, 157-186.

Levin, A, and Lin, C-F., 1993, "Unit Root Tests in Panel data: Asymptotic and Finite sample Properties", Discussion Paper 92-23, UCSD.

Lopez, C., Christian, J., Murray and D. Papell, 2002, "state of the art unit Root Tests and the PPP Puzzle", University of Houston, Department of Economics, Working Papers in Economics.

Lothian, J., R., and M., P., Taylor, 1996, “Real Exchange Rate Behaviour: The Recent Float from the Perspective of the Past Two Centuries,' Journal of Political Economy, vol. 104 (3) June, 488-509. 
Lothian, J., R., 1997, "Multi-Country Evidence on the Behaviour of Purchasing Power Parity Under the Current Float,' Journal of International Money and Finance, vol.16 (1) February: 19-35.

Lyhagen, J., 2000, "Why not Use Standard Panel Unit Root Test for Testing PPP" Working Paper, Stockholm School of Economics.

MacDonald, R., 1994, International Money and Finance, Blackwell Publishers, Oxford UK and Cambridge USA.

MacDonald, R., 1996, "Panel Unit Root Tests and Real Exchange Rates", Economics Letters, 50, 7-11.

Maddala, G.S and S. Wu., 1999, "A Comparative Study of Panel Data Unit Root Tests and a Simplified Test", Oxford Bulletin of Economics and Statistics, Special Issue, 0305-9049.

LTD.

Maddala, G.S, 2002 "Introduction to Econometrics", John Wiley \& Sons,

MacDonald, R., and Marsh, I. 1994, "Forecasting the Exchange Rate: Are Economists Equally Bad, or Are 'N' Heads Better than One?, Mimeo, University of Strathclyde.

Mark, N., C., 1990, "Real and nominal exchange rates in the long run: An empirical investigation,' Journal of International Economics, vol.28 (1/2) February: 115-36.

McCoskey , S., and Kao, C., 1998, "A Residual-Based test of the Null of Cointegration in Panel Data", Econometric reviews, 17, 57-84.

McCoskey, S., and Kao, C., 1999,'”Comparing Panel Data Cointegration Tests with an Application of the "Twin Deficits" Problem", mimeo.

Meese, R., and K. Rogoff, 1998, "Was it Real? The Exchange rate-Interest

Rate Differential Relation Over the Modern Floating Rate Period", Journal of Finance, 43, 3.

Murray, C., J and D., Papell, 2002, "The Purchasing Power Parity Persistence Paradigm", Journal of International Economics, 56, 1-19.

Ng., and Perron, P., 1999, “ PPP May not Hold After All: A Further Investigation" Boston University, Department of Economics, Working Paper.

Ng., and Perron, P., 2001, " Lag Length Selection and the Construction of Unit Root Tests with Good Size and Power”, Econometrica 69, 1519-1554.

O Connell, P.G.J., 1998, “ The Overvaluation of Purchasing Power Parity”, Journal of International Economics, 44, 1-19.

Oh, K., 1996, "Purchasing Power Parity and Unit Root Tests Using Panel Data" Journal of International Money and Finance, 44, 15, 1-19.

Papell, D.H., 1997, "Searching for Stationarity: Purchasing Power Parity Under the Current Float", Journal of International Economics, 43, 313-332.

Papell, D., H., and Theodoridis, H., 2000, "The Choice of Numeraire Currency in Panel Tests of Purchasing Power Parity", Houston University, Department of Economics Working Papers.

Papell, D., H., 2002, "The Great Appreciation, the Great Depreciation, and the Purchasing Power Parity Hypothesis", Journal of International Economics, May, 5182.

Pedroni, P., 1996, "Fully Modified OLS for Heterogeneous Cointegrated Panels and the Case of Purchasing Power Parity", Indiana University, Department of Economics. 
Pedroni, P., 1997, “Panel Cointegration: Asymptotic and Finite Sample Properties of Pooled Time Series Tests with an Application to the PPP Hypothesis", Manuscript, Indiana University.

Pedroni, P, 1999, “ Critical Values for Cointegration Tests in Heterogeneous Panels with Multiple Regressors", Oxford Bulletin of Economics and Statistics, special issue (1999) 0305-9049.

Pesaran, M., H., 2003, "A Simple Panel Unit Root Test in the Presence of Cross Section Dependence", Cambridge University, Department of Economics Working Papers in Economics.

Phillips, P., C. and Hyungsik R. Moon, 1999, "Linear Regression Limit Theory for Nonstationary Panel Data", Econometrica 67, 1057-111.

Phillips, P., C. and Hyungsik R. Moon, 2001, "Non-Stationary Panel Data Analysis: an Overview of Some Recent Developments", Econometric Reviews, 19, 263-286.

Phillips, P., C., and D., Soul, 2003, "Dynamic Panel Estimation and Homogeneity Testing Under Cross Section Dependence", Cowles Foundation Discussion Papers.

Rogoff, K., 1996, "The Purchasing Power Parity Puzzle", Journal of Economic Literature, 34, 647-668.

Sargan, J., D., and Bhargava, A., 1983, "Maximum Likelihood Estimation of Regression Models with First Order Moving Averages Errors when the Roots Lies on the Unit Circle", Econometrica, 51, 799-820.

Sarno, L. and M.P. Taylor, 2002, "Purchasing Power Parity and the Real Exchange Rate", IMF Staff Papers, 49, 1, 65-105.

Taylor, M.P and Sarno, L., 1998, " The Behaviour of Real Exchange Rates During The Post Bretton Woods Period", Journal of International Economics, 46, 281-312.

Taylor, M.P, 2003, "Purchasing Power Parity", Review of International Economics, 11, 3, 436-452.

Taylor, M., P., and D., A., Peel, 2000, "Nonlinear Adjustment, Long-Run Equilibrium and Exchange Rate Fundamentals", Journal of International Money and Finance, 19, 33-53.

White, H., 2001, "Asymptotic Theory in Econometrics" Academic Press, London, $2^{\text {nd }}$ Edition.

Wu, Y., 1996, "Are Real Exchange Rates Nonstationary? Evidence from a Panel-Data Test", Journal of Money Credit and Banking, 28, 54-61. 